\title{
An Anatomical study of Cleft hand in North - East population of Assam
}

\author{
Bandita Tatwade ${ }^{1}$, Monali Hiwarkar ${ }^{2}$ \\ ${ }^{1,2}$ Assistant Professor, Department of Anatomy, Index Medical College Hospital \& Research Centre, Indore.
}

\section{Abstract}

Introduction: Cleft hand or Ectrodactyly or Split Hand is a rare form of congenital hand disorder in which there is deficiancy of one or more central rays of the hand. The hand presents with a V-shaped gap situated in the centre of the palm. The condition may occur alone or maybe associated with anomalies of foot, syndactly, polydactyly, triphalangeal thumb, transverse bones in the hand or maybe part of Ectrodactyly Ectodermal dysplasia Cleft (ECC) Syndrome. Aims and Objectives: To find out the sex ratio and incidence of laterality (unilateral or bilateral) of cleft hand in North East population of Assam. Subjects and Methods: This study included 31 children between age group of 3 years to 8 years with hand deformities who were brought to the Plastic Surgery Department, Gauhati Medical College, Guwahati for aesthetic correction within a time span of 2 years. Only those cases who had central defects of hand were included \& those with other syndromic anomalies were excluded. For this detailed clinical and radiological examination was done to evaluate the extent of bone or tissue involvement and to find out any syndromic association of the condition. Results: Out of 31 cases, 10 cases were had Unilateral and 21 cases had Bilateral Cleft Hands. It was seen that out of 31 cases, 22 were males and only 09 were females indicating that male to female ratio of the deformity is 2.44 .Thus, males were more affected than females. Conclusion: Most of the cases presented with absence of the middle finger and central tissue of the affected hand since birth. The embryological basis has been highlighted to throw light into such a catastrophe where both males and females were affected and showed unilateral or bilateral involvement of the hand leading to cosmetic and functional debility. Therefore, the study revealed that males were more affected than females and bilateral involvement of the hands were common than unilateral involvement.

Keywords: Ectrodactyly, Cleft Hand, Apical Ectodermal Ridge.

Corresponding Author: Dr. Monali Hiwarkar, Assistant Professor, Department of Anatomy, Index Medical College Hospital \& Research Centre, Indore.

Received: May 2019

Accepted: May 2019

\section{Introduction}

Deficiencies of the central portion of the hand have been named as cleft hand, split hand lobster claw, ectrodactly by many authors. ${ }^{[1]}$ The incidence is 1 to 4 in 100000 live births. $^{[2]}$

Hand deformities with a central failure of formation of tissues are categorised as typical cleft hand. It is a rare form of a congenital disorder in which the development of hand is disturbed. The incidence varies from 1 in 90,000 to 1 in 100,000 births depending on the classification used. ${ }^{[3]}$ It is also known as Ectrodactyly or Split Hand. It can be unilateral or bilateral and can occur alone as a sporadic case or maybe associated with a syndrome with a familial history. Sporadic cases of cleft hand are known as atypical cleft hand or symbrachydactyly and presents a more severe malformation of the hand. Flatt ${ }^{[4]}$ has described cleft hand as a functional triumph and a social disaster. The typical cleft hand has a fissure in the palm and is almost normal in size. Literature shows that cleft hand was described centuries ago when Ambroise Pare ${ }^{[5]}$ in 1575 first described a case of cleft hand. Hartsink (1770) wrote the first report of true cleft hand. However, the knowledge of cleft hand became clear only at the end of nineteenth century when the genetic and embryological aspects of the disorder was correlated and explored anatomically and clinically. ${ }^{[6]}$

\section{Aims and objective:}

To find out the sex ratio and incidence of laterality (unilateral or bilateral) of cleft hand in North East population of Assam in children between 3 to 8 years of age.

\section{Subjects and Methods}

A total of 31 children between 3 to 8 years of age were meticulously examined who presented to the Department of Plastic Surgery in Guwahati Medical College and Hospital, Gauhati during a time span of two years i.e. October. 2011 to October 2013. The number of male and female cases were recorded. Their detailed history was taken; emphasis was given to family history and antenatal history of maternal teratogen exposure. Clinical examination was done to evaluate which hand was more affected i.e. right or left or both and other associated congenital anomalies were looked 
for; cleft lip, cleft palate, syndactyly, foot deformities etc. Only those cases who had central defects of hand were included \& those with other syndromic anomalies were excluded. For this detailed clinical and radiological examination was done to evaluate the extent of bone or tissue involvement and to find out any syndromic association of the condition. Plain radiographs, AP and Lateral view of affected and normal hand were taken to see the degree of malformation.

\section{Results}

The present study includes total of 31 cases of cleft hand in which 10 children (10 hands) had unilateral cleft hand and 21 children (42 hands) had bilateral cleft hand. Therefore a total of 52 cleft hands were studied.

A wide $\mathrm{V}$ - shaped gap was seen in 22 cases which extended into the palm. In rest of the 9 cases only phalanges of the middle finger were missing. The radiograph of the affected hand revealed absence of all the phalanges of the middle finger. The gap between the third and fourth metacarpals was increased with the latter being smaller in size.

\section{Incidence of Laterality}

Out of 31 cases, 10 cases were found to be Unilateral and 21 cases had Bilateral Cleft Hands. The cases had isolated defects of hand only and they had no other congenital anomalies. The right hand was more affected than the left hand in unilateral cases. In unilateral cleft hand, 8 cases had right hand deformity and in remaining 2 cases left hand was deformed. The findings are tabulated below:

Table 1: Percentage of Unilateral \& Bilateral Cleft Hand Cases
\begin{tabular}{|l|l|l|}
\hline Cases & Total Cases & Percentage \% \\
\hline Unilateral CH & 10 & $32.2 \%$ \\
\hline Bilateral CH & 21 & $67.8 \%$ \\
\hline
\end{tabular}

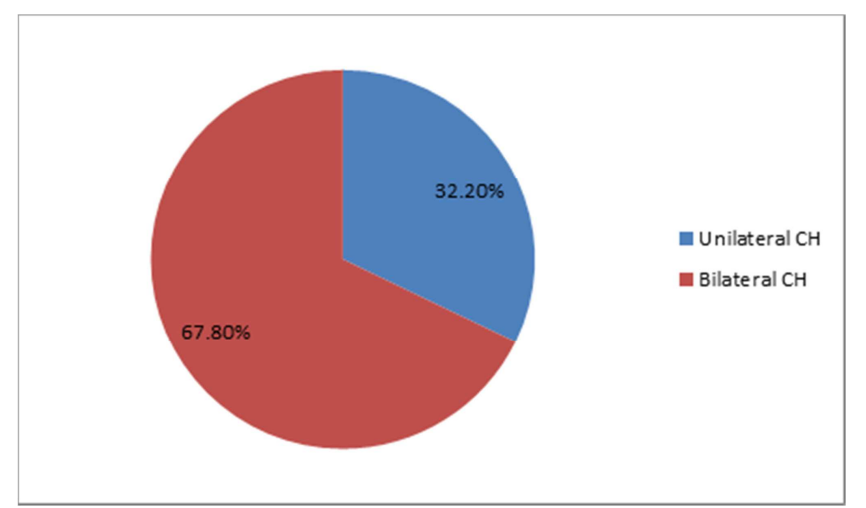

Figure 1: Percentage of Unilateral \& Bilateral Cleft Hand Cases

\section{2. Sex-Ratio}

It was seen that out of 31 cases, 22 were males and only 09 were females indicating that male is to female ratio of the disease is 2.44 and males were more affected than females.

Table 2: Percentage of Cleft hand Deformity in males and females.

\begin{tabular}{|l|l|l|l|}
\hline S. No. & Sex & Number & Percentage $\%$ \\
\hline 1. & Male & 22 & $71 \%$ \\
\hline 2. & Female & 09 & $29 \%$ \\
\hline
\end{tabular}

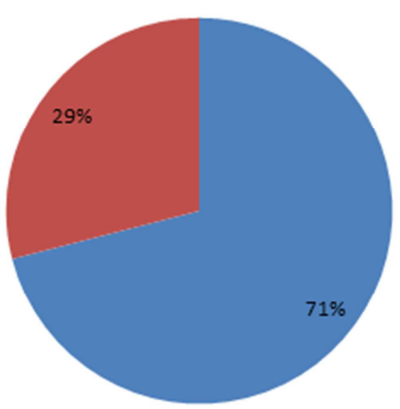

Male

a Female

Figure 2: Percentage of Cleft hand Deformity in males and females.

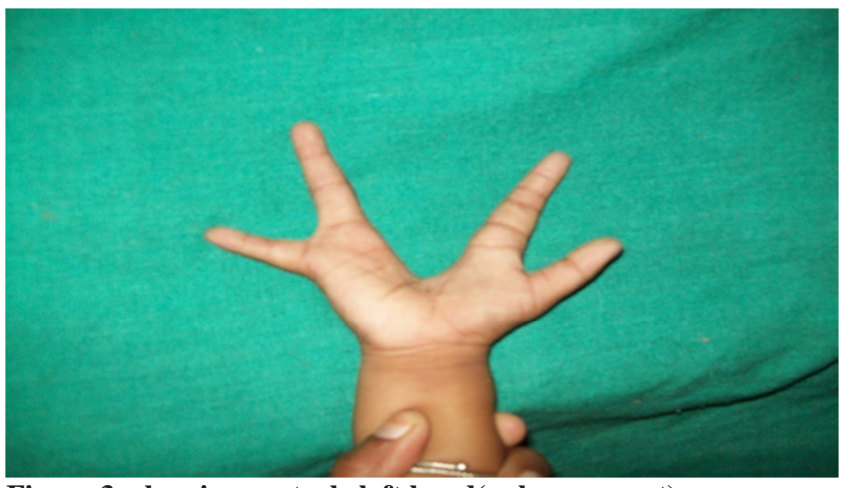

Figure 3: showing central cleft hand(palmer aspect)

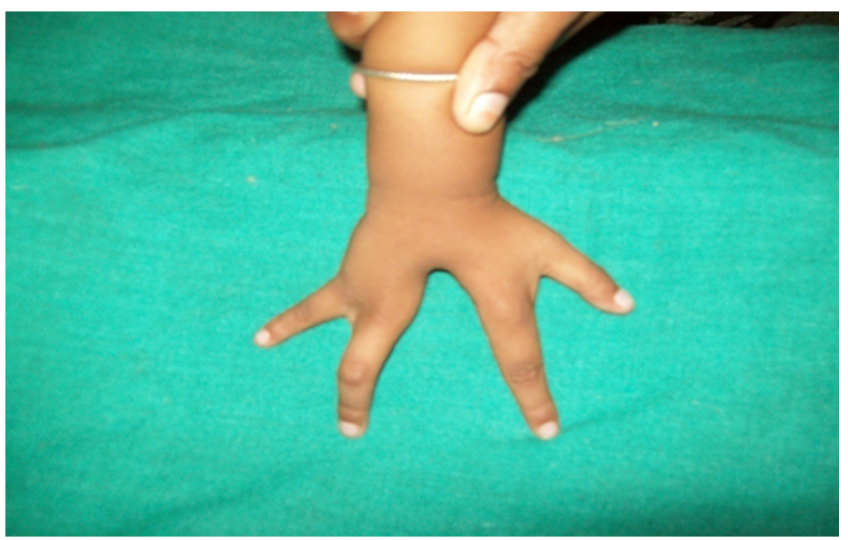

Figure 4: showing central cleft hand (dorsal aspect)

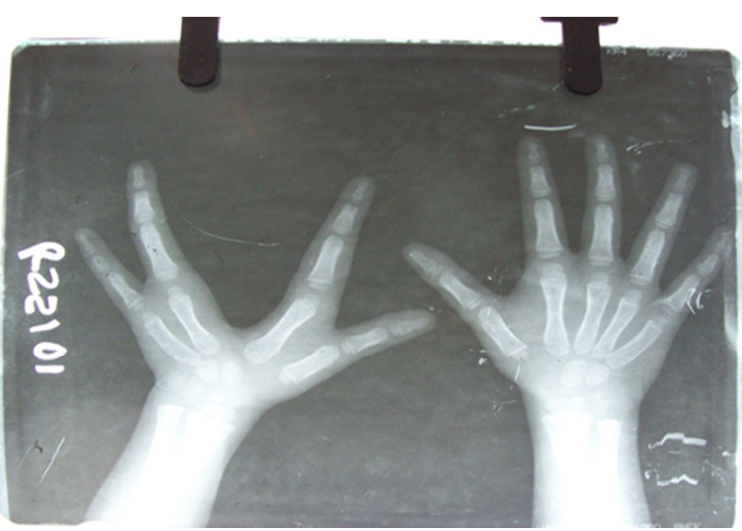

Figure 5: showing missing metacarpel and phalanges of affected hand (AP view) 


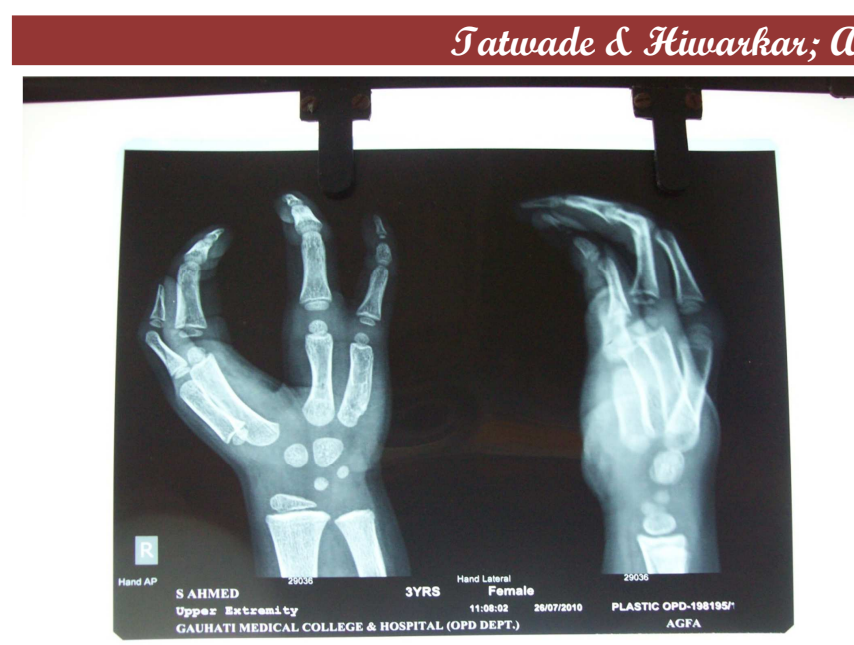

Figure 6: showing lateral view of affected hand

\section{Discussion}

Cleft hand or Ectrodactyly also known as Lobster Claw Hand, is a rare deformity which presents with a cleft of variable extent usually in the central ray and is commonly associated with syndactyly and abnormalities in the adjacent digits and sometimes with malformation of the feet.

While the term ectrodactyly literally means "missing digits", it is now used as a descriptive term for a central ray anomaly that presents clinically as a central cleft of the hands or feet. Historically, terms such as "Lobster Claw" and split hand have been used to describe this defect which results from absence, or reduction, of one or more of the three central digits. The earliest known description of cleft hand was that by Pare ${ }^{[5]}$ although Barsky ${ }^{[7]}$ suggested that this report represented two fingered hemimelia rather than true cleft hand. Central ray defects, according to Swanson's modified classification, represent terminal longitudinal limb anomalies. $^{[8]}$

A typical claw hand/ foot is U- shaped defect where index, long and ring fingers are absent and metacarpals are present. ${ }^{[9]}$ According to Lange, cleft has been classified into 2 types - typical and atypical. Typical cleft hand is manifested by V- shaped gap with associated syndactyly, polydactyly, transverse bones, abnormalities of feet etc. It is autosomal dominant condition and may show familial inheritance. . The incidence of typical cleft hand is $1: 90,000$ births and 1:120,000 population. Atypical cleft hand occurs in 1:150,000 births and 1:200,000 population. In our study also we have found 21 cases with a wide V- shaped gap which was radiologically confirmed but they had no associated congenital anomalies.

Congenital Disorders: Cleft Hand that there are many variations in the presentation of cleft hand of which absence of central portion of the hand is the main feature. The deficiency varies from absent phalanges to absent individual finger to monodactyly or even the absence of all the digits. ${ }^{[9]}$ The depth of the cleft depends upon the remaining metacarpals; if present, the cleft is shallow and when absent, cleft is deep. ${ }^{[10]}$ We seen similar findings in our study also. Barsky $^{[7]}$ also described two types of cleft hand in his study. One is typical cleft hand with a deep palmer cleft which separates two central metacarpals and one or more rays maybe absent and the existing digits maybe of unequal length. The variety was categorized as atypical cleft hand where rays were absent and only short radial and ulnar digits may remain.

Blauth and Falliner ${ }^{[11]}$ collected 303 cases from literature including their 35 cases. They found bilateral cleft hand in 163 cases $(56 \%)$ and unilateral in 140 cases (44\%). Bilateral cleft hand cases had a familial history of which $50 \%$ were inherited as autosomal dominant disease. The association of cleft foot is even less, with less than one-third of having this deformity. ${ }^{[10]}$

PD Burge in their study concluded that cleft hand is usually bilateral and familial which was found in our study also i.e. $67 \%$ cases had bilateral cleft hand and only $32.25 \%$ cases had unilateral cleft hand. ${ }^{[12]}$

Birch-Jensen ${ }^{[13]}$ found that $58 \%$ of cases of cleft hands were bilateral with an equal sex distribution. These clinical findings were confirmed by Barsky. ${ }^{[7]}$ The majority of cases of cleft hand in our study also had bilateral involvement of the hands but sex ratio showed male preponderance.

Tarek et $a{ }^{[14]}$ in their study revealed that failure of differentiation and duplication deformities were the most frequent, with polydactyly was the most common anomaly encountered. The mean age of presentation was 6 years and female to male ratio was 1.46:1. Their study included 64 patients, 26 males and 38 females. This can be explained by social concepts as the presence of such anomalies in a female child threatens her social life and marriage opportunity. They also found that cleft hand was more commonly bilateral $(60 \%)$ which is seen in our study also $(67 \%)$ and syndactyly was the most frequent associated anomaly; however, these results may be biased by the limited number of cases.

According to Sahasrabudhe $\mathrm{PB},{ }^{[15,16]} 60 \%$ showed male preponderance of cleft hand which tallies with our study in which we have found $71 \%$ male involvement.

Thakkar et al, ${ }^{[17]}$ found in their study that cleft hand maybe a part of Ectrodactyly, Ectodermal dysplasia, Cleft lip/palate (EEC) Syndrome which is a rare autosomal dominant condition presenting with ectrodactyly, hypopigmented hair, peg shaped teeth with defective enamel and cleft lip and palate. In our study we have excluded cases with other congenital anomalies, taking into account only the deformed hand of the children.

Maisel's ${ }^{[18]}$ centripetal theory proposes that clefting can range from simple central soft tissue defect to complete absence of all digits which indicates a progressive teratogenic spectrum. A wedge shaped defect of the apical ectoderm of the limb bud is thought to cause cleft hand. In this study most of the cases had central ray deficiency indicating that central tissue anomaly maybe the commonest mode of occurrence.

Developing limb is dually contributed by lateral plate and somatic mesoderm. Within the proliferated cells of lateral flank, the cells of the adjacent somites which will form muscles, vessels and nerves start invading. Such proximodistal outgrowth is directed by signals from the Apical Ectodermal Ridge (AER) present at distal tip. Fibroblast growth factors (FGFs) acts as key mediators to strengthen it. The Zone of Polarizing Activity (ZPA), a cluster of cells at the posterior border of the limb near the flank modifies the antero- posterior pattern. ${ }^{[19]}$ 


\section{Embryological Significance}

By the end of 4th week of development the limbs become visible from the ventrolateral body wall. This bud consists of a mesenchymal core covered by a layer of cuboidal ectoderm which gradually thickens at the distal border of the limb bud forming the Apical Ectodermal Ridge. This ridge is vital in axis orientation, outgrowth and digitations. When the embryo reaches 6th week of development, the terminal portion becomes flattened to form hand and foot plates. ${ }^{[20]}$ The molecular interactions that occurs during limb development greatly influences the process of limb morphogenesis. Due to these interactions the process of digit development commences as the Apical Ectodermal Ridge begins to fragment and notched digital rays are formed. On day 50 the digits are webbed and on day 52 they become separate. Thus, the process of digits formation involves fragmentation of AER and subsequent apoptosis within digital interspaces. ${ }^{[21]}$

Once the limb outgrowth is initiated Bone Morphogenic Proteins expressed in the ventral ectoderm induce formation of AER by signaling through homeobox genes MSX2. After the ridge is established, it expresses FGF- 4 and 8 which maintain the progressive zone which is the rapidly proliferating population of mesnchymal cells adjacent to the ridge. Thus, a wedge shaped degeneration of the apical ectoderm of the limb is thought to lead to cleft hand.

\section{Conclusion}

Cleft hand produces a particular challenge because function may be good but the appearance may be socially unacceptable. Early surgery should be aimed at preventing worsening of the deformity. Cleft hand malformations have been extensively studied in previous literatures. Cleft hand deformity is secondary to wedge-shaped defect in primary hand plate. The apical ectodermal bridge does not develop normally and there is a defect in it's differentiation. In this study analysis of data both clinically and radiologically revealed that cleft hand showed a male preponderance $(71 \%)$ and females were less affected. Cases with bilateral cleft hand $(67 \%)$ were more common than unilateral cases; and in the later cases right hand was more involved than left hand.

\section{References}

1. Poznanski AK. The Hand in radiologic diagnosis. WB
Saunders: Philadelphia; 1974 , pg. 183- 7.

2. Rogala EJ, Wvnne Davis R, Little John A, Gormley J, Congenital Limb Anomalies : frequency and etiological factors. J Med Genetics 1974; $11: 221-23$.

3. Sadler TW. Teratology. 11th Edition. New Delhi: Wolter Klauer Health (India) Pvt. Ltd; 2009. Clinical correlates. InSkeletral system (ch. 9). Langman's medical embryology; pp. 136-41.

4. Flatt AE. Cleft hand and central defects. In: Flatt AE, editor. The care of cogenital hand anomalies. St Louis, MO: Quality Medical Publishing; 1994. p. 337

5. Pare A . Les oeuvres de M Ambroise Pare. Paris: Gabriel Boun, 1575:5-8.

6. Tsuge K, Ischii S, Lieba Y. Report of the Japanese Society for Surgery of the Hand, Committee on Congenital Malformations of the Hand. Orthop Surg (Jpn) 1980;31:1959-1963.

7. Arthur J Barsky. Cleft Hand: Classification, incidence and treatment : Review of Literature and report of nineteen cases. J Bone Joint Surg Am. 1964; 46: 1707 - 1720.

8. Tekin M, Ohle C, Johnson DE, et al. Counseling dilemmas in EEC syndrome. Genet Couns 2000;11:19-24.

9. Miller CI, Hashimoto K, Shwayder T, et al. What syndrome is this? Ectrodactyly, ectodermal dysplasia, and cleft palate (EEC) syndrome. Pediatr Dermatol 1997;14:239-240.

10. Scwabe GC, Mundlos S. Genetics of congenital hand malformation. Handir Mikrochir Plast Chir. 2004;36:85-97.

11. Blauth W, Falliner A. Morphology and classification of cleft hands. Handchir Mikrochir Plast Chir 1986;18:161-195.

12. Burge PD. Developmental anomalies of the hand. In: Benson M, Fixsen J, Macnicol M, Parsch K, editors. Children's Orthopedics and Fractures. London: Springer-Verlag; 2010. p. 339-55.

13. Birch-Jensen A. Congenital deformities of the utpper extremities. Copenhagen: Ejnar Munksgaard, 1949.

14. Tarek Abulezz, Mohamed Talaat, Asem Elsani,1 and Karam Allam Congenital hand anomalies in Upper Egypt Indian J Plast Surg. 2016 May-Aug; 49(2): 206-213.

15. Sahasrabudhe PB, Kulkarni MD. Unusual case of cleft hand. Indian J Plast Surg 2007;40:205-8

16. Rodini ES, Richieri-Costa A. EEC syndrome: report on 20 new patients, clinical and genetic considerations. Am J Med Genet 1990;37:42-53.

17. Thakkar S, Marfatia Y. EEC Syndrome sans Clefting: Variable Clinical Presentation in a family. Indian Jr Dermatol Venerol Leprol. 2007; 73: 46 - 48.

18. Maisels DO. Lobster-claw deformities of the hand. Hand 1970;2:79-82. 4. Maisels DO. Theory of Pathogenesis of Lobster Claw deformities. Hand 1970; 2:79.

19. Moore Keith L, Persaud T.V.N: The developing human clinically oriented embryology, Chapter 17, The Limbs, 7th Edition, SAUNDERS First Indian Reprint 2003, pp 41023

20. McCarroll HR. Congenital anomalies: A 25-year overview. J Hand Surg Am. 2000;25:1007-37.

21. Miorra T. Cleft hand involving only the ring and small finger. J Hand Surg 1988; 13A: 530-535.

Copyright: (C) the author(s), publisher. Academia Anatomica International is an Official Publication of "Society for Health Care \& Research Development". It is an open-access article distributed under the terms of the Creative Commons Attribution Non-Commercial License, which permits unrestricted non-commercial use, distribution, and reproduction in any medium, provided the original work is properly cited.

How to cite this article: Tatwade B, Hiwarkar M. An Anatomical study of Cleft hand in North - East population of Assam. Acad. Anat. Int. 2019;5(1):122-125.

DOI: dx.doi.org/10.21276/aanat.2019.5.1.28

Source of Support: Nil, Conflict of Interest: None declared. 